\title{
El primer Partido Comunista del Paraguay, la Internacional Comunista y la guerra del Chaco
}

\author{
The first Communist Party of Paraguay, \\ the Communist International and the Chaco War
}

Charles Quevedo

Universidad Nacional de Asunción

dpgcs@yahoo.com

(Paraguay)

Lorena Soler

Universidad de Buenos Aires

Consejo Nacional de Investigaciones Científicas y Técnicas

lorenamarinasoler@gmail.com

(Argentina)

Recibido: 25-06-2019

Aceptado: 11-12-2019

Publicado: 05-06-2020 


\title{
Resumen
}

Este trabajo indaga los primeros años del Partido Comunista del Paraguay tomando como ejes su inserción como sección nacional de la Internacional Comunista y sus relaciones con esa organización mundial fundada a través de su órgano regional: el Secretariado Sudamericano. En primer lugar, se ocupa de los conflictos que tuvieron lugar entre la sección nacional paraguaya y la Komintern en un contexto de inminencia de la Guerra del Chaco (1932-1935). Estos desacuerdos estuvieron relacionados con las posibilidades de la sección paraguaya de aplicar las tácticas contra la guerra impulsadas por la Internacional Comunista y con la crisis interna del Partido Comunista de Argentina (1927-1928) que tuvo como consecuencia la escisión del grupo liderado por Penelón. Posteriormente, estudia algunos aspectos de la actividad de los comités antiguerreros en Paraguay, expresión de los movimientos antibélicos impulsados por el Komintern que buscaban transformar la guerra en revolución social. Por último, se analiza el período posterior al final del conflicto bélico que dio lugar a la "revolución Febrerista" (1936), movimiento que aglutinó a diferentes sectores unificados por el nacionalismo y el antiliberalismo. Para entonces, la estrategia de la Komintern, a partir de su VII Congreso en 1935, había experimentado un viraje priorizando la formación de frentes populares, lo que llevó al comunismo paraguayo a integrar la coalición que dio sustento al gobierno de Rafael Franco (1936-1937). La nueva estrategia permitió al PCP, salir del aislamiento político y crecer en la inserción en el mundo obrero paraguayo.

Palabras Clave: Partido Comunista del Paraguay, Internacional Comunista, Guerra del Chaco, frentes populares.

\begin{abstract}
This paper explores the first years of the Paraguayan Communist Party, based on its insertion as a national section of the Communist International and its relations with this world organization through its regional body: the South American Secretariat. On the first hand, this work takes into account, the conflicts that took place between the Paraguayan national section and the Komintern in a context of imminence of the Chaco War (1932-1935). These disagreements were both related to the possibilities of the Paraguayan section to apply the anti-war tactics promoted by the Communist International and to the internal crisis of the Communist Party of Argentina (1927-1928) that resulted in the split of the group led by Penelón. On the second hand, this paper studies some aspects of the activity of the anti-war committees in Paraguay, a political expression of anti-war movements promoted by the Comintern which sought to transform war into social revolution. Finally, this work analyses the period after the end of the war conflict in which the "revolución Febrerista" (1936) rose up, as a movement that unified different sectors under nationalism and anti-liberalism. By then, the strategy of the Komintern, since its VII Congress in 1935, had undergone a turn by prioritizing the formation of popular fronts, which led Paraguayan communism to join the coalition that supported the government of Rafael Franco (1936-1937). The new strategy allowed the PCP to emerge from political isolation and grow into the insertion in the Paraguayan working world.
\end{abstract}

Keywords: Communist Party of Paraguay, communist International, Chaco War, popular fronts 


\section{Introducción}

En su clásica obra "La Internacional Comunista y la revolución latinoamericana (19191943)", Manuel Caballero (1985) dedicaba unos escasos párrafos a las actividades del comunismo paraguayo, afirmando -a modo de justificación- que, durante mucho tiempo, el Partido Comunista del Paraguay (en adelante, PCP) era más conocido en el extranjero por el interminable sufrimiento de sus militantes en las cárceles que por su relevancia en la escena política paraguaya. Si bien es cierto que hasta el presente es apenas conocida su historia, el PCP no careció de relevancia política. A lo largo de las casi cuatro décadas que transcurren entre 1928, año de su fundación, y 1965, signada por la derrota de la guerrilla del Frente Unido de Liberación Nacional (en adelante, FULNA), el comunismo paraguayo estuvo presente y fue un actor importante en todos los avatares de la convulsionada historia política nacional e internacional.

El presente trabajo se inscribe en la sucesión de esfuerzos realizados por historiadores, intelectuales y militantes políticos desde el final del régimen del General Stroessner (1954-1989) por rescatar y reconstruir la historia del comunismo paraguayo. Para hacerlo, indaga los primeros años del partido a partir de su inserción como sección nacional de la Internacional Comunista (1919), -también conocida como III Internacional o Komintern- a través de su órgano regional: el Secretariado Sudamericano (en adelante, SSA). Los años inaugurales del PCP están marcados por dos rasgos centrales: por un lado, la agudización del conflicto fronterizo entre Paraguay y Bolivia que daría lugar al estallido de la guerra del Chaco (1932-1935) y, por otro, la implementación de la estrategia política del llamado "tercer período", conoci- da como "clase contra clase", propiciada por la Komintern a partir de su VI Congreso en 1928. Esta orientación izquierdista promovía la profundización de la confrontación social a partir de una visión catastrofista del capitalismo mundial, que auguraba su inminente caída.

Posteriormente, el trabajo se ubica en una coyuntura histórica nodal marcada por el viraje en el VII Congreso de la Internacional Comunista, realizado en agosto de 1935 en Moscú -cuando priorizó la estrategia de los frentes populares- y el contexto nacional de la pos guerra del Chaco, que dará lugar a la formación de la particular coalición política del gobierno de Rafael Franco (1936-1937). La participación del PCP, al igual que la de amplios sectores ajenos a los partidos tradicionales, como las organizaciones obreras -la Confederación Nacional de Trabajadores y luego la Confederación de Trabajadores Paraguayos- campesinas y de mujeres con impronta antiimperialista, dan cuenta de una coyuntura de cambio que debe ser vista de cara a las necesarias reactualizaciones heurísticas. Así, la estrategia de frentes populares llevó al PCP a vincularse con otros grupos políticos y sociales que habilitaba la nueva ola nacionalista de la posguerra y la experiencia política de la denominada "revolución febrerista".

Para dar cuenta de dicha problematización, el estudio hace un esfuerzo por demostrar cómo los cambios en las estructuras sociales y sus actores, en un contexto internacional determinado, produjeron las condiciones de posibilidad para dar inicio a la formación del PCP. Este aporte intenta invertir los términos del abordaje epistemológico presente en los estudios partidarios, e indagar sus prácticas políticas en la doble coyuntura internacional y local, estudiando cómo el cambio de estrategia de la Ko- 
mintern tuvo su correlato en la del PCP. Teniendo en cuenta que es aún débil e incipiente la producción bibliográfica dedicada al comunismo paraguayo, el artículo adopta una forma básicamente descriptiva y busca producir materiales para un uso propiamente analítico en trabajos posteriores. A manera de hipótesis, se sostiene que la emergencia de nuevos sujetos que presionaban por la ampliación de los márgenes del espacio político -consecuencia de cambios en la estructura económica del $\mathrm{Pa}-$ raguay-, y la irradiación del comunismo como efecto del impacto de la revolución rusa, habilitaron el surgimiento de un partido comunista en Paraguay. Además, sostiene que las acciones antiguerreras, en el contexto de la guerra del Chaco, produjeron los primeros acercamientos entre el movimiento comunista y las organizaciones obreras paraguayas -hasta entonces hegemonizado por anarquistas y socialistas. Luego, en la posguerra, el viraje de la estrategia hacia la formación de frentes populares dio lugar a una creciente inserción del comunismo en el mundo obrero paraguayo.

Empíricamente el trabajo se apoyará en periódicos, archivos personales, documentos del PCP, publicaciones del SSA como La Correspondencia Sudamericana, y periódicos de las organizaciones sindicales y partidarias asociadas a la Internacional Comunista, principalmente El Trabajador Latinoamericano, el Boletín del Comité Organizador del Congreso Antiguerrero, así como los documentos vinculados al PCP que forman parte de los acervos de la Internacional Comunista, -guardados en el Archivo Estatal Ruso de Historia Sociopolítica- que fueron recientemente compilados por Víctor Jeifets y Andrey Schelchkov (2018).

\section{Guerra y revolución. Los años 1920 y 1930}

Como en otros países de América Latina, el Paraguay de la década de 1920 también fue expresión de las mayores contradicciones y expresiones políticas que cuestionaban los márgenes del orden demoliberal en marcha (Ansaldi, 2003). Diversos e importantes hechos ocurrieron entre los años 1922 y 1932: una guerra civil de dimensiones nacionales comandada por facciones del Partido Liberal (Cívicos y Radicales); la defensa del presidente constitucional Eusebio Ayala por las armas de los cadetes de la escuela militar y la Liga de Obreros Marítimos; la creación de la primera asociación de pequeños propietarios nacionales; las manifestaciones estudiantiles que reclamaban la defensa militar del Chaco y la "toma" de la ciudad de Encarnación, declarada "zona liberada de la voracidad capitalista"; y la solicitud del presidente José R. Guggiari (1929-1932) de su propio juicio político son sólo algunas imágenes que permiten describir la agitación de la época. De allí que la Guerra del Chaco (1933-1936), por un conflicto limítrofe que se arrastraba desde la firma del pacto Varela-Derqui de $1852,{ }^{1}$ no hizo sino exacerbar los problemas que desde la década de 1920 tensionaban el funcionamiento de ese orden social. En efecto, desde mediados de los años 1920, la agitación social adoptó ribetes inesperados cuando las huelgas y las manifestaciones callejeras, e incluso las intentonas insurreccio-

1. En 1878 se produjo un laudo arbitral del presidente de los Estados Unidos, Rutherford Hayes, que le asignó a Paraguay la zona en disputa. Bolivia continúo con sus reclamos basándose en los antiguos límites coloniales de la Audiencia de Charcas, mientras Paraguay insistía en la existencia de expediciones colonizadoras efectuadas desde Asunción, las ordenaciones territoriales realizadas por la corona española desde el siglo XVI y las ordenanzas de los intendentes. 
nales -que por primera vez lograban penetrar el interior del país-, pusieron en alianza a un pequeño pero gravitante movimiento obrero con los campesinos, los jóvenes del movimiento estudiantil ${ }^{2}$ y algunos sectores medios de la burguesía, bajo un discurso nacional que impulsaba la guerra y tensaba cada vez más la relación con el Gobierno.

Como ha indicado Aníbal Miranda (1979), tanto las variaciones de precios en los productos del mercado mundial como los ciclos económicos de la economía internacional impactaban en el Paraguay -un país agroexportador- de forma directa, salvo en los sectores exclusivamente ligados a la economía externa como los frigoríficos, la explotación yerbatera o la taninera. De ahí que, durante los años 1920, el auge de las exportaciones algodoneras incidiera sobre la ampliación del mercado interno -con la incorporación de grandes masas de campesinos- y provocara una modernización social y política desconocida. En tanto el cultivo de algodón es una actividad realizada para la subsistencia y en manos de pequeños agricultores y de producción, no es casual que se inicien ahí los primeros movimientos de campesinos organizados. Al compás de estas transformaciones comenzaba también un incipiente proceso de industrialización-como ocurría con la produción de azúcar y la reapertura de varios frigoríficos- "que alimentaría las expectativas de aquel grupo social que se iba configurando alrededor de la manufactura nacional y el crecimiento de la clase obrera" (Flecha, 1995, p. 535).

2.En este contexto se llevó a cabo la reforma universitaria en Paraguay (1926), liderada por un puñado de jóvenes agrupados en la Federación de Estudiantes de Paraguay que luego serían quienes participarían de la refundación del PCP, en 1933-1934.
En este contexto entonces y como efecto del auge económico, surgieron alrededor de setenta gremios que abarcaban a artesanos, obreros metalúrgicos, de frigoríficos, ferroviarios, marítimos y tranviarios, trabajadores de las tanineras y del interior del país (Rivarola, 2013). Al mismo tiempo, se crearon federaciones y ligas de sindicatos por sectores de producción. A la central anarquista, que se reorganiza en 1916 con el nombre de Centro Obrero Regional del Paraguay (en adelante, CORP) se suma la primera central socialista llamada Federación Obrera del Paraguay (en adelante, FOP). ${ }^{3}$ En ese período también surge, independiente de las centrales anarquista y socialista, la Liga de Obreros Marítimos (en adelante, LOM), como escisión de la Federación Naval creada en 1916. La LOM se constituirá en la más combativa y política de las organizaciones sindicales de ese período.

E1 crecimiento organizativo del movimiento sindical trae aparejado la multiplicación de las reivindicaciones y la intensificación de los conflictos laborales. Entre los años 1912 y 1920, tienen lugar unas 75 huelgas, algunas de ellas de carácter general o con participación de varios gremios (Rivarola, 2013). La extensión de la acción sindical de los trabajadores y la incorporación de los agricultores a la lucha "repercutieron en el seno de los partidos tradicionales a los que les preocupaba el inusitado despliegue de fuerzas populares integradas por obreros, campesinos y el Comité de Acción social" (Gaona, 2007, p. 135). En efecto, en este contexto de conflictividad social y acompañando la oleada latinoamericana de formación de los partidos comunistas de los años 1920,

3. La central de tendencia socialista fue creada en 1912 como Unión Gremial del Paraguay (UGP), con la participación de obreros gráficos, sastres, orfebres y zapateros. 
se pueden rastrear las primeras tentativas de formación del PC en Paraguay.

A diferencia de otras experiencias, como ha señalado Rivarola (2014), el PCP no nació de la escisión del ala radical del partido socialista preexistente, sino que sus antecedentes pueden encontrarse entre los años 1923 y 1924. En rigor, la primera expresión organizada del marxismo en Paraguay fue el Partido Socialista, con el liderazgo del obrero Rufino Recalde Milessi (1885-1957), tipógrafo y dirigente sindical que había creado el Partido Obrero en 1914. Tres años más tarde se lo llamó "Socialista” y, en 1918, Socialista Revolucionario. ${ }^{4}$ Entre los meses de febrero y octubre de 1924, bajo el secretariado del albañil Donato Cáceres, algunos obreros e intelectuales que actuaban en el campo sindical fundaron en Asunción una organización denominada Comité de Acción Social, y pusieron en circulación, en noviembre de ese mismo año, el periódico Bandera Roja. Como señala Francisco Gaona (2007), su aparición fue denunciada por sectores reaccionarios como la infiltración soviética en el Paraguay, y, por primera vez, empezó a emplearse la palabra "comunista" como pretexto para la represión contra obreros y campesinos.

Los materiales de la Conferencia Nacional Preparatoria para el III Congreso del PCP contenían referencias acerca de la actividad realizada en Asunción por un grupo marxista entre los años 1922 y 1923 y de su lucha en contra del Gobierno, que "cumplía el papel de lacayo del imperialismo norteamericano e inglés". Y ya para el año siguiente, "un grupo comunista decidiría enviar un delegado a Buenos Aires para tomar contacto con los líderes

4.Con dicha denominación ganó una banca de diputado en 1923, pero arbitrariamente el gobierno le impidió asumir cargo (Bonzi, 2009, p. 35). del Partido Comunista Argentino (en adelante, PCA), y discutir con ellos la cuestión del desarrollo de un movimiento revolucionario de la clase obrera en Paraguay" (Quevedo, 2014, p. 94).

Ante la casi total ausencia de documentos de archivo relacionados con las primeras organizaciones comunistas paraguayas, se pueden rastrear sus actividades y el proceso de ingreso a la órbita de la Internacional Comunista (en adelante, IC) y del SSA a través de las publicaciones ligadas a esta última y los informes de los dirigentes comunistas argentinos que acompañaban la evolución del comunismo paraguayo. Así, La Correspondencia Sudamericana -el órgano del SSA de la IC- publicaba en su primer número de abril de 1926, un artículo redactado por Pedro Romo con el título de "El imperialismo en el Paraguay”. El escrito, estaba basado en una carta enviada desde Asunción por militantes comunistas y refería a las medidas represivas impulsadas por el gobierno paraguayo en contra del naciente movimiento comunista. Además, se mencionaba a los "candidatos comunistas" que en las elecciones "fueron tomados presos deportados con otros muchos en las selvas vírgenes del Brasil" (p. 27). Probablemente, el texto hacía alusión a los candidatos obreros del Partido Socialista, liderados por Rufino Recalde Milessi y Cayetano Raimundi, que participaron en las elecciones legislativas el 30 de setiembre de $1923 .{ }^{5}$

5. El diario Patria, del opositor Partido Colorado había publicado un mes después, una nota con el título de "Democracia idealista. El secuestro como arma electoral", fechada el 5 de octubre de 1923 y firmada por Cayetano Raimundi en la cual se acusa al gobierno de Eligio Ayala de apresar a los candidatos unos días antes de las elecciones y trasladarlos al interior del país, liberándolos recién después de finalizar el acto electoral. 
En una carta de junio de 1926, José Fernando Penelón, -principal fundador del PCA y máxima autoridad del SSA de la IC- informaba a Moscú que el SSA había establecido contactos en Paraguay con algunas personas aisladas que simpatizaban con la Komintern y, al mismo tiempo, había ampliado los vínculos con el pequeño PCP que existía en la ilegalidad, debido, según la evaluación de Penelón, a su inactividad (Jeifets y Jeifets, 2013). De acuerdo con el informe de Penelón, el PCP prefería no salir a la arena política y evitaba celebrar eventos públicos, ya que ello significaría la deportación al Brasil de sus pocos activistas y la liquidación de toda actividad comunista. Lazar Jeifets y Víctor Jeifets (2013) señalan que el SSA “era completamente pasivo en desarrollar la actividad comunista en el país, limitándose a los contactos esporádicos con el efímero partido comunista” (p. 94).

En 1926, La Correspondencia Sudamericana, acusaba recibo de otra carta de los comunistas paraguayos: en ella se informaba acerca del proceso de reorganización del PCP y del posible nombramiento de un nuevo Comité Central. Los paraguayos señalaban que se había convocado a una asamblea, pero posteriormente se resolvió postergarla para solicitar al SSA de la IC "todas las indicaciones necesarias sobre cuestiones de organización, a fin de encarar seriamente el problema de reorganización del Partido". 6 Al respecto, el editor del periódico indicaba que la "organización celular" facilitaría el trabajo de organización emprendido y que el Partido debe procurar dar vida política a las organizaciones de base. Al mismo tiempo, tres cuestiones debían reclamar la atención del Comité Central del Partido según el editor: la

6. (11 de septiembre de 1926). La Correspondencia Sudamericana, p. 23. Arquivo Edgard Leuenroth Unicamp, Campinas, Brasil. cuestión sindical, la cuestión campesina y la lucha contra el imperialismo. Sobre esta última cuestión se señalaba que todos los esfuerzos debían tender a la formación de una sección de la Liga Anti-Imperialista. Según se aclaraba, no se trataba de crear una organización comunista, sino de que los comunistas tomen la iniciativa o colaboren activamente junto a otros elementos intelectuales y obreros ajenos al Partido dispuestos a iniciar esas tareas. Se hacía hincapié en la necesidad de iniciar una campaña de reclutamiento sindical de las células comunistas, así como el trabajo entre los campesinos.

Recién durante los preparativos del IV Congreso de la Internacional Sindical Roja (1928), Pedro Romo, secretario general del PCA, establecería contactos con Moisés Drelijman, uno de los dirigentes paraguayos, con el objetivo de recabar información sobre la situación del movimiento obrero y las posibilidades de desarrollar actividades comunistas en Paraguay. Con el apoyo de Romo, quién remitió materiales de propaganda e instrucciones para la reorganización del grupo asunceno, finalmente llegó a concretarse la fundación del PCP el 19 de febrero de 1928. Ese día, alrededor de cincuenta personas en asamblea eligieron al secretario general del PCP, Lucas Evangelista Ibarrola un procurador judicial según sus declaraciones en Moscú. Como integrantes del Comité Ejecutivo designaron a Martín Báez, de ocupación platero; a los estudiantes Juan B. Denis y Asdrúbal Pane; al comerciante polaco Moisés Drelijman; a Eugenio Charles, Juan Nunes, Víctor Valenzuela, F. Mancuello y Yegros (Buzó Gómez, 2008).

En su primer manifiesto, " $\mathrm{i}$ los ciudadanos de la República!", se daba a conocer el programa del naciente partido, cuyo objetivo político 
era "crear por medio de la revolución social un Gobierno de obreros, campesinos y soldados, como primera etapa para el logro del socialismo completo (...) y del paso ulterior al comunismo" (Churilov y Petrujin, 1994, p. 19).

El 19 de abril de 1928, el Secretariado Latino del Comité Ejecutivo de la Internacional Comunista remitió una carta al Comité Ejecutivo del PCP firmada por su jefe, el suizo Jules Humbert-Droz. En ella, el jefe del Secretariado Latino confirmaba haber recibido, por intermedio del SSA de la Internacional Comunista de Buenos Aires, el Manifiesto del 19 de febrero de 1928 que anunciaba la formación de un partido comunista en el Paraguay. ${ }^{7}$ Humbert-Droz exhortaba a los comunistas paraguayos a mantener relaciones más seguidas con el secretariado de la IC y solicitaba un informe sobre la situación económica y política y sobre las organizaciones sindicales y campe-

7. Con relación a los orígenes del Secretariado Sudamericano (SSA) de la IC, Piemonte (2015) señala que en 1925, Humbert-Droz ya advertía que los trabajos de formación comunista que llevaban adelante las secciones nacionales sudamericanas de la Komintern eran deficitarios, y que el Partido Comunista de la Argentina (PCA) era el que había alcanzado mayor grado de desarrollo en materia de preparación teórico-política de sus cuadros y afiliados. De esa consideración se desprendía que el PCA era el instrumento más adecuado para conseguir el rápido desarrollo de la formación comunista de dirigentes y afiliados, y la coordinación del trabajo de los partidos comunistas de los países vecinos. La creación del SSA en Buenos Aires, en febrero de 1925, fue consecuencia de esas comprobaciones. Por otra parte, el surgimiento del SSA obedecía al reconocimiento de la importancia relativa que había alcanzado el subcontinente latinoamericano dentro del esquema táctico de la IC, lo cual terminó consolidándose en su VI Congreso de 1928. Asimismo, el SSA impulsó la creación de una publicación en castellano destinada al análisis del movimiento revolucionario en América Latina. Éste fue el origen de La Correspondencia Sudamericana, publicación quincenal editada en Buenos Aires a partir de abril de 1926 (Piemonte, 2017).

112 sinas existentes, así como sobre la presencia de un movimiento antiimperialista. Demandaba, además, información amplia sobre el partido recién fundado y pedía a los paraguayos que le hicieran llegar sus periódicos y manifiestos directamente, si fuera posible, a una dirección de Moscú indicada al final la carta (Hotel Lux Chambre 20. Tverskaia 56, Moscou, URSS) o a otra alternativa en Suiza en caso de que, por razones de seguridad, fuese imposible remitirlos a la Unión Soviética (Jeifets y Schelchkov, 2018, p.1153).

En su respuesta a Humbert-Droz, el 5 de junio de 1928, Lucas Ibarrola describía la siguiente situación:

En el Paraguay la lucha social tiene arraigo de tiempo atrás, pero desgraciadamente se viene desarrollando en una forma desordenada sin un programa concreto de conquista reivindicatoria. Las agrupaciones casi siempre en pugna unas con otras no han podido orientar un ideal definitivo. $Y$ esta es la causa primaria de la formación del PC en la convicción de que, siguiendo el camino ya abierto en Europa, puede conducir a un fin más eficiente (Jeifets y Schelchkov, 2018, p. 1168).

Con relación a la persecución policial y la posibilidad de actuar legalmente, Ibarrola señalaba que el Comité Ejecutivo debía dirigir los trabajos con prudencia y precaución, ya que era objeto de constantes advertencias y vigilancia por parte de las autoridades y aun de la prensa burguesa, debido al temor de que el nuevo partido cayera bajo la influencia de la IC. Ibarrola informaba que el conflicto fronterizo paraguayo-boliviano por el territorio del Chaco estaba vinculado a las disputas entre los imperialismos norteamericanos e ingleses. 
Jules Humbert-Droz había recomendado, al mismo tiempo, que el SSA de la Internacional Comunista estableciera contactos con el recientemente fundado PCP y le ofreciera el apoyo necesario dentro de las posibilidades. Sin embargo, el SSA estaba prácticamente paralizado por la crisis interna del PCA entre los años 1927 y 1928. Dos posturas definidas se enfrentaban dentro de esta organización del PCA en esos años. Por un lado, la línea encabezada por José Fernando Penelón que se oponía a tomar la política internacional de la Unión Soviética como centro de las preocupaciones del comunismo argentino y privilegia$\mathrm{ba}$, por sobre el internacionalismo, el desarrollo de un trabajo nacional (Piemonte, 2017). Por otro lado, la posición liderada por Rodolfo Ghioldi, que buscaba congeniar a ultranza con los lineamientos establecidos por la IC (Piemonte, 2015).

A pesar de que la incorporación de nuevos adherentes era una de las prioridades que se había propuesto el SSA, su líder José Fernando Penelón no había hecho demasiados esfuerzos para expandir la influencia de la Komintern en la región durante los dos años en los que estuvo al frente del Secretariado. ${ }^{8}$ Otros miembros del Secretariado, como Rodolfo Ghioldi y Victorio Codovilla, también estaban inmersos en la lucha interna del PCA, con lo cual Pedro Romo, secretario general del PCA, era el único

8. Piemonte (2015) señala que José Penelón “no realizó grandes esfuerzos por llevar a cabo desde la Argentina y con el PCA como epicentro la coordinación de las tareas que el comunismo debía desarrollar en Sudamérica, lo que redundó en la conformación de una red de relaciones endeble que no llegó a consolidarse”. En el mismo sentido, Lazar Jeifets y Víctor Jeifets (2010) hacen notar que Penelón no estaba interesado en promover la formación de un Partido Comunista en Ecuador, y si exponía el caso a Moscú era con la sola intención de obtener fondos. miembro activo y el que había apoyado tanto la fundación del PCP como el envío de la carta de los comunistas paraguayos al Comité Ejecutivo de la IC.

En un evidente acto de proselitismo personal, Romo había informado al Comité Ejecutivo de que la fundación del PCP, ante la parálisis del SSA, había sido fruto exclusivo de su trabajo y de la iniciativa local de los paraguayos (Jeifets y Jeifets, 2012). La carta de Humbert-Droz, anteriormente mencionada, revelaba que la Internacional Comunista tenía escasas referencias sobre el nuevo partido. La resolución de las disputas internas del $\mathrm{PCA}^{9}$-con la consolidación de una nueva conducción partidaria dirigida por los hermanos Ghioldi y Victorio Codovilla-, y las divergencias con el SSA en relación a cuestiones estratégicas frente al conflicto paraguayo-boliviano por el Chaco, tendrían como consecuencias la intervención y la reorganización del recién fundado PCP, y la destitución de su primer secretario general, Lucas Ibarrola.

9. De acuerdo con Hernán Camarero (2011) la disputa interna se inició en junio de 1927 en torno a la cuestión sindical, el papel de los grupos idiomáticos y la acción en el Concejo Deliberante de Buenos Aires, y tuvo con consecuencia la escisión, en diciembre de 1927, del sector de los adherentes a Penelón -quién contaba con gran prestigio personal por el papel que cumplió en el surgimiento del partido y su actuación en el Concejo Deliberante-. Los "penelonistas" constituyeron otra organización denominada inicialmente Partido Comunista de la Región Argentina, y, más tarde en 1930, Concentración Obrera. Con el nuevo partido, Penelón logró revalidar en dos ocasiones su mandato y continuó presente en el escenario político de Buenos Aires en las siguientes tres décadas. Codovilla lo reemplazó como secretario del SSA de la IC, pero recién después del alejamiento del PCA de Penelón y su reemplazo por el sector de Rodolfo Ghioldi, Victorio Codovilla y Pedro Romo, los partidos comunistas del resto de Sudamérica -entre ellos el PCP- lograron su afiliación a la IC, con el apoyo del SSA (Piemonte, 2017). 
Señalando las limitaciones y debilidades del PCP, su secretario general afirmaba que: "El P. no ha sustentado hasta hoy ninguna plataforma de reivindicaciones. Su labor, pobre, ha sido circunstancial", y concluía que: "El P., pues, como organización no existe" (Jeifets y Schelchkov, p. 1169) y que los obreros no acudían comúnmente al partido porque no les alcanzaba el tiempo. Los dirigentes del PCA cuestionaban ese punto de vista ya que si los obreros no tenían tiempo sería imposible hablarles de la revolución social. En evidente discordancia con las tesis de la IC, el secretario general del PCP opinaba que los dirigentes del partido debían ser intelectuales, ya que los obreros no estaban aún capacitados. Lazar Jeifets y Víctor Jeifets (2012) señalan que las discretas actividades partidarias y las limitaciones ideológicas de los dirigentes paraguayos no suscitaban mucho entusiasmo en los nuevos líderes del SSA (p. 127). Además, los historiadores rusos indican que había otras razones para que hubiera disconformidad, en tanto el PCP no había adoptado las veintiuna condiciones para la admisión a la Internacional Comunista.

Victorio Codovilla -nuevo secretario del SSA después del alejamiento de Penelón- no estaba conforme con el papel de Romo como fundador de nuevas secciones de la Tercera Internacional. Además, el comunista argentino desconfiaba de Ibarrola, fundamentalmente debido a que el paraguayo había llegado a establecer vínculos de confianza con su antecesor Penelón y, al igual que éste, consideraba que las secciones nacionales de la IC debían tener cierta autonomía en la determinación de sus líneas políticas. De hecho, los primeros partidos comunistas de la región gozaron de ciertos grados de libertad antes de entrar en la órbita del SSA bajo la dirección de Codovilla (Piemonte, 2017 y Ulianova, 2007). Así, acu- saba a Ibarrola de ser el "Penelón paraguayo": "Ibarrola es, -escribe Codovilla-, en los límites paraguayos, una fiel reproducción de Penelón; pero con mostachos". ${ }^{10}$

El dirigente ítalo-argentino manifestaba su fastidio ante la insistencia de Ibarrola en señalar los obstáculos para desarrollar una propaganda antiguerrera, en un contexto de crecimiento de los sentimientos patrióticos en el Paraguay. Con realismo sostenía que una línea antiguerrera expondría a un débil e incipiente PCP a una fuerte represión bajo la acusación de traición a la patria, lo cual acabaría con toda actividad comunista. Poco tiempo después, el curso de los acontecimientos vendría a confirmar las presunciones de Ibarrola.

En un informe -Le P.C. du Paraguay-, presumiblemente escrito por Humbert-Droz, en 1928, en base a informes de Codovilla, se describía al PCP y a Ibarrola en los siguientes términos:

E1 P.C. del Paraguay es más bien un pequeño grupo de camaradas que un verdadero partido en el sentido orgánico de la palabra. No posee una organización de base ni una organización para la dirección. La dirige un "caudillo" -Ibarrola- de una manera individualista, que nada tiene de comunista. Ibarrola es un "intelectual" pequeño-burgués desclasado, vanidoso e incapaz de hacer cualquier trabajo serio. (Jeifets y Schelchkov, 2018, p. 1157).

A pesar de las objeciones que pesaban sobre Ibarrola, Codovilla se vio obligado a aceptar que fuera a Moscú como delegado en el VI

10. Codovilla, V. (30 de abril de 1929). La expulsión de Ibarrola. Aclarando el alcance de esa medida y denunciando la inaudita especulación de Penelón. La Correspondencia Sudamericana, 10, p. 17. 
Congreso Mundial de la Tercera Internacional, ya que según el argentino "los camaradas trabajadores con mayor nivel político" no tenían posibilidades de viajar. Cuando, en vísperas del VI Congreso Mundial, Ibarrola llegó a Buenos Aires el SSA se limitó a tomar nota de sus informes, a facilitarle el pasaje a la Unión Soviética, y a lograr la incorporación y la afiliación a la Komintern en 1928. ${ }^{11}$

Durante el desarrollo del VI Congreso de la IC en Moscú, entre los meses de julio y agosto de 1928, la intervención de Ibarrola -que fue recogida entre los documentos de Informes y Discusiones del Congreso- se concentraba en describir las actividades de los imperialismos inglés y yanqui en el Paraguay en el contexto del conflicto paraguayo-boliviano, y las luchas del PCP:

Los imperialismos inglés y yanqui -señalaba Ibarrola- se disputan la supremacía (...) El Partido Comunista combate con éxito las intervenciones de los dos imperialismos denunciando las maniobras del imperialismo yanqui que quiere apropiarse de la región petrolifera del Chaco (Jeifets y Schelchkov, 2018, pp. 364-365).

La Internacional Comunista había dedicado especial atención al conflicto bélico desde sus inicios. El Comité Pro Confederación Sindical Latino Americana (en adelante, CPCSLA), de orientación comunista, había lanzado, en el mismo mes de diciembre de 1928, un llamado a los trabajadores paraguayos y bolivianos - publicado en El Trabajador Latinoamericanocon el que los alertaba sobre los peligros de la inminente guerra:

11. Codovilla, V. (30 de abril de 1929). La expulsión de Ibarrola. Aclarando el alcance de esa medida y denunciando la inaudita especulación de Penelón, $L a$ Correspondencia Sudamericana, p.10.
Trabajadores de Bolivia y del Paraguay: La guerra que se prepara no es la vuestra. El contenido real del litigio por la frontera del Chaco Boreal, es una prolongación de la lucha entre el imperialismo inglés y el americano (...) (Hernández, 2004, p.142).

Sin embargo, el apoyo masivo y popular que en Paraguay recogía la contienda bélica colocó al partido frente a una severa crisis, aunque también dotó al PCP de una visibilidad internacional única: el pequeño partido adquirió un carácter prioritario en la agenda de la Internacional Comunista. Según señalaba Humbert-Droz en 1929, el PCP se encontraba en una situación de gran responsabilidad, ya que era la primera de todas las secciones con la obligación histórica de aplicar las tácticas comunistas contra la guerra. La IC trataba de impulsar firmemente la esencia de la política leninista sobre la guerra -el derrotismo- intentando reconvertirla en una guerra civil contra los explotadores, en la hipótesis de que una conmoción tan grande abría posibilidades inéditas para la revolución social. Además, la centralidad del PCP en esa coyuntura estaba resaltada por el hecho de que Bolivia carecía, por entonces, de un partido comunista en actividad. A pesar de que en 1928 Carlos Mendoza Mamani había fundado el Partido Comunista Clandestino, el mismo tenía escasa incidencia y los comunistas bolivianos se refugiaban en una pequeña agrupación denominada Partido Laborista desde la que difundían algunas consignas e ideas, pero sin atreverse a desarrollar acciones públicas (Hernández, 2004).

Por otra parte, Humbert-Droz (1929) criticaba una resolución de la Unión Obrera del Paraguay que había recibido desde Asunción, y denunciaba que el documento sobre las amenazas de guerra era netamente social-patriota 
y preparaba a la clase obrera para el conflicto armado y no contra éste. El secretario del Comité Ejecutivo de la IC pedía explicaciones al Comité Ejecutivo del PCP sobre cómo la Unión Obrera del Paraguay había podido adoptar una política social-patriota.

En febrero de 1929, en Montevideo (Uruguay), organizaciones gremiales dirigidas por comunistas realizaron la Conferencia Sindical Sudamericana contra la Guerra, en la que se votó la creación del Comité Continental contra la Guerra. De ella participaron los paraguayos Rufino Recalde Milesi, José Barbosa y Francisco Gaona, ${ }^{12}$ por la Unión Obrera, y Obdulio Barthe, Carlos Irala y Leopoldo Ruiz, por el Centro Obrero Regional del Paraguay.

En una reconstrucción erudita de cómo intervino la IC en relación al conflicto bélico, José Luis Hernández (2004) da cuenta de las enormes dificultades para lograr el "encuadre" de las organizaciones obreras y de los propios cuadros dirigentes del partido a la lectura en clave imperialista del conflicto, que proponía el órgano central. ${ }^{13}$ Así, Vittorio Codovilla, en

12. En el $5^{\circ}$ Congreso Sindical Roja, que se realizó el 7 de junio de 1930 y en el que participaron Francisco Gaona, Rufino Recalde Milesi y Daniel Villalba, se los volvió a acusar de reformistas. El representante argentino Contreras tuvo a su cargo las palabras inaugurales de la Conferencia Sindical Latinoamericana, en la cual dedicó, según el testimonio de Gaona, un capítulo especial al movimiento obrero paraguayo "totalmente desafortunado, pues fue denunciado como un movimiento vacilante $y$ reformista”. En la misma dirección fueron acusados por el secretario general de la Confederación Sindical Unitaria de México, el cual instó a que la delegación paraguaya definiera públicamente si estaba o no con la Internacional Sindical Roja (AG-02-14, Archivos personales de Francisco Gaona).

13. Recordemos que la interpretación dominante de la historiografía posterior a la guerra estuvo centrada en la puja por los intereses del petróleo; la norteamericana 116 el marco de la primera conferencia comunista realizada en Buenos Aires, en junio de 1929, se refirió en forma descarnada a la debilidad de los grupos partidarios de ambos países:

En este contexto, Dellepiane, seudónimo de quien se desempeñaba como delegado del PCP en la conferencia de Buenos Aires, intentaba trasmitir la complejidad que adquiría el hecho bélico en el contexto paraguayo ante las debilidades de un partido de reciente formación, el poco elevado nivel ideológico de la militancia paraguaya y la poca experiencia que el PC tenía en relación con las guerras. Sin embargo, reconocía que el principal obstáculo estaba en el éxito que habían tenido las clases dominantes paraguayas para lograr una concurrencia masiva al conflicto armado:

Una intensa campaña patriótica o, mejor dicho chauvinista, donde la burguesía paraguaya reeditó las consignas de la "defensa de la patria en peligro" (...) Esa propaganda

Standard Oil, titular de los yacimientos bolivianos, y la inglesa Royal Dutch Shell, con fuertes intereses en Paraguay y Argentina, intentaban impedir la expansión de su rival en los territorios entonces en disputa. Hoy la historiografía renovó las interpretaciones y considera a los grupos hegemónicos y las clases subalternas, en una época imbuida de nacionalismo. 
guerrera y chauvinista cundió entre las masas y todos corrieron a los cuarteles. ${ }^{14}$

A pesar de ello, Victorio Codovilla terminaría acusando a Ibarrola de "adoptar una política pequeño burguesa y oportunista-chauvinista, frente a la inminencia de la guerra promovida por el imperialismo" (Bonzi, 2009, p. 43).

Todo esto motivó la intervención del Comité Central del PCP, que terminó deponiendo al primer secretario general del partido. La reorganización del PCP en 1929, bajo la tutela del SSA, promovió a Martín Báez al cargo de secretario general. El primer Acta del proceso de reorganización (Acta No. 1 de la Reorganización del Partido) describe el clima en el cual se desarrollaban entonces las actividades partidarias:

El c. Codovilla en breves palabras indicó la plataforma política que debe seguir el Partido Comunista de acuerdo con la disciplina internacional, y a la vez, prometió ayudar materialmente y moralmente y todo lo que está al alcance del Secretariado S.A. de la I.C. Hubo un debate entre los compañeros Báez e Ibarrola. Aquel lo acusó sobre la supuesta malversación de fondos, todo esto fue desmentido categóricamente por el c. Codovilla (Jeifets y Schelchkov, 2018, pp. 1162-1163).

El proceso de refundación del PCP, entre los años 1933 y 1934, "se hizo bajo el signo de una intervención manifiesta de la Komintern y su aparato regional” (Quevedo, 2014. p. 95). Los principales dirigentes del Nuevo Ideario Nacional (1929), ${ }^{15}$ Obdulio Barthe y Oscar Creydt,

14. (1929). La Situación Internacional de América Latina $y$ los Peligros de Guerra, $3^{\text {ra }}$ sesión, p. 48. Arquivo Edgard Leuenroth, Unicamp, Campinas.

15. El Nuevo Ideario Nacional (1929) fue un documento se incorporarían al PCP para su refundación, en 1934, en el marco de la Conferencia de Lobos (provincia de Buenos Aires, Argentina). De ella participaron, entre otros, Leonardo Dielma, Aurelio Alcaraz (nuevo secretario general), Juan Orué, Emiliano Paiva Palacios, Carlos Peña, Tomás Mayol, Marcelino Cáceres y, probablemente, su mujer, Enriqueta de Cáceres, dirigente de las mercaderas y primera mujer en ejercer la secretaría provisoria del PCP (1934). A pesar de estar encarcelado en Buenos Aires junto a miembros y colaboradores de Soviet, la revista teórica del Partido Comunista Argentino, ${ }^{16}$ Creydt fue elegido como miembro del Comité Central (Piamonte, 2016, p. 204). Barthe también fue designado en ausencia por encontrarse en prisión en Asunción con otro militante, Perfecto Ibarra, por sus actividades antiguerreras.

\section{"Guerra a la guerra”. Los comunistas y las actividades antiguerreras}

En 1933, un año después de haberse iniciado la guerra en el Chaco Boreal, se desarrolló en Montevideo el Congreso Antiguerrero Continental convocado por los comunistas, con la presencia de más de 400 delegados prove-

político dirigido "a los trabajadores y hombres jóvenes de todos los partidos. El documento fue escrito a un año de que Bartolomeo Vanzetti respondiera la carta que Creydt le hiciera llegar, en la que expresaba su solidaridad con los obreros condenados a muerte. Recuperado de http://vientofuerte.com/last/articulo.php?art=22195\#. $\mathrm{VtBeuOZpftc}$

16. Entre ellos, Rodolfo Ghioldi, Paulino González Alberdi, Héctor P. Agosti, Miguel Contreras, Orestes Ghioldi, José Peter y Juan Nuñez, como consecuencia de un proceso llevado a cabo al amparo de la nueva legislación represiva anticomunista vigente en Argentina. 
nientes de todo el continente. El evento fue presidido por el intelectual argentino Aníbal Ponce, y, notablemente, en el Presidium no había ningún boliviano y solamente un paraguayo, Oscar Creydt (Stefanoni, 2014, p. 31). Aún cuando el Congreso intentaba impulsar la unidad de acción contra la guerra, -incluso incorporando a otras corrientes de izquierda entre las cuales los trotskistas y anarquistas-, pronto las diferencias se pusieron en evidencia obstruyendo la conformación de un frente único. Los anarquistas planteaban no tomar las armas ni enrolarse en los ejércitos, apostando por la deserción; los comunistas, por su parte, proponían empuñar las armas y transformar la guerra entre países en una guerra civil entre clases sociales opuestas (Hernández, 2004).

Los Comités antiguerreros paraguayos realizaron un denodado esfuerzo en las actividades de agitación y propaganda antiguerrera, difundiendo panfletos que llamaban a resistir a los reclutamientos y sabotear el transporte de armas. En los Departamentos de Guairá, Caazapá e Itapúa la policía tuvo que reprimir las "montoneras" conformadas por campesinos que se resistían al reclutamiento (Rivarola, 2013).

El 20 de julio de 1933, el Ministerio de Guerra y Marina de Paraguay emitió un circular dirigido a los jefes de reparticiones militares y comandos de unidades, informando que el Ministerio del Interior había incautado un plan de acción comunista. El impreso que había caído en poder de las unidades de inteligencia del gobierno paraguayo era el "Proyecto aprobado por la Conferencia Paraguaya contra la Guerra, en Montevideo (Sesión del domingo 2 de abril de 1933)" que establecía un plan a ser cumplido en un plazo de tres meses, empezaba señalando que: "Vista la debilidad de las fuerzas, la Conferencia resuelve concentrar los trabajos sobre los siguientes puntos: a) Obreros marítimos portuarios; b) Obreros ferroviarios; y, c) Campesinos de la zona de Caazapá, Sosa, Maciel, Villarrica y Charará" (Fernández, 1987, p. 87).

Estaba previsto solicitar al PCA la presencia de un delegado en Asunción, como representante del Comité Central Antiguerrero, con el objetivo de impulsar las tareas establecidas. Asimismo, sería conformada una comisión técnica especial, estrechamente vinculada con los comités marítimos y ferroviarios, encargada de establecer contactos entre el proletariado y el ejército, $y$ realizar tareas para ganar posiciones entre los soldados.

El documento establecía que la tarea principal del delegado en los puntos "donde existen ya grupos de campesinos en pie de lucha”, consiste en dar a ese principio de lucha económica un claro sentido político de lucha de clase contra la guerra imperialista. Se planteaba vincular las incipientes formas de resistencia campesina contra las requisas y el reclutamiento, -que se daban principalmente en forma de huida a los bosques-, con reivindicaciones mayores: la tierra; la negativa a pagar arriendo; la rebaja de fletes; o la toma de tierras de los grandes hacendados. Se buscaba ampliar el objetivo de las luchas, llevando a los grupos campesinos refugiados en bosques a luchas abiertas contra los terratenientes y autoridades. El trabajo ideológico consistía en hacer comprender a los campesinos "la verdadera causa de la guerra". En el plan, se establecieron también tareas de infiltración en el ejército a través de reservistas. Por último, se impulsaba la conformación de un Comité de Unidad Sindical Clasista del Paraguay (en adelante, CUSC) 
En sus memorias, Barthe (2009) señala lo siguiente:

Nosotros no dimos la línea de deserción, dimos la línea de ir al frente y confraternizar con los soldados, hacer una labor educativa que cree las condiciones para un levantamiento popular (p. 72).

Bajo el título de "El desarrollo de las luchas antiguerreras en Paraguay" (1934), Soviet, publicaba una carta de la dirección del PCP sobre la situación en el país. El escrito daba cuenta de episodios resistencia de los campesinos a la requisa de alimentos y ganado para el frente, y la formación de "montoneras", grupos de campesinos que rechazaban el reclutamiento y el trabajo forzado. Los comunistas alentaban estas acciones de resistencia con la consigna de "Resistencia a las requisas. $\mathrm{Ni}$ un grano de maíz, poroto, ni mandioca, ni burro, ni vaca, ni caballo, ni trabajo gratis para la guerra imperialista". ${ }^{17}$ La carta narraba también el destino de militantes comunistas que eran descubiertos difundiendo consignas de confraternización en el frente y eran obligados a integrar pelotones suicidas en el frente, o sumariamente fusilados, como el caso de Demetrio Flores. E1 Teniente Chase Sosa describía así la situación:

El más grave problema que debió estudiar y resolver el Estado Mayor General no fue precisamente el de los "emboscados", sino el del personal ya veterano que bajaba del Chaco con permiso de 20 o 30 días, y que al término de su licencia no demostraba ya interés de regresar al Chaco. La perniciosa influencia del comunismo internacional hizo verdadero estrago en este orden que se precisó combatir con dura y acaso heroica

17. (11 de noviembre de 1934). El desarrollo de las luchas antiguerreras en Paraguay, Soviet, 2, 11, pp. 18-24. Archivo Cedinci, Buenos Aires decisión, mediante la acción enérgica de las Policías Militares (Capital y Campaña) (Fernández, 1987, p. 85).

En julio de 1935, se puso fin a las hostilidades en el Chaco. La Internacional Comunista ingresaba en una nueva etapa: dejaba atrás las estrategias de "clase contra clase" y ahora buscaba la alianza con la burguesía liberal, bajo la orientación del Frente Popular. El viraje de la Internacional y la nueva estrategia política revolucionaria coincidieron con el liderazgo indiscutido que adoptó la figura de Oscar Crey$\mathrm{dt},{ }^{18}$ a quien le resultaba insuficiente entender el conflicto entre las dos naciones latinoamericanas como parte de las disputas imperialistas. En efecto, el nuevo contexto posbélico y el VII Congreso Mundial de la Internacional, realizado en agosto de 1935 en Moscú, coincidieron con el nuevo liderazgo del PCP. En rigor, con Oscar Creydt y Obdulio Barthe reaparecía "un grupo de militantes más proclives al anarquismo o al sindicalismo de acción directa, diferente al de los primeros comunistas de la década de 1920" (Quevedo, 2014, p. 95). $\mathrm{Y}$ esos mismos líderes estudiantiles, que integraron posteriormente la directiva del ahora recreado Partido Comunista, "constituyeron la izquierda del movimiento franquista desde el '36' (Rivarola, 2015, p. 3).

\section{Los comunistas en el movimiento febrerista}

El fin de la guerra devino en una fuerte crisis económica, consecuencia de la paralización

18.Ver documento: (17 de diciembre de 1931) Sobre el carácter de la guerra en América Latina. La Internacional, núm. 3401. Arquivo Edgard Leuenroth, Unicamp, Campinas. 
bélica y un desértico regreso de los soldados. Para los de origen urbano, el regreso significó la ausencia de trabajo y el aumento abrupto de la desocupación; en tanto que para los de origen rural, la confirmación de su condición de campesinos sin tierra. En efecto, la Guerra del Chaco había expuesto la brutalidad de una estructura desigual y los primeros rasgos de una estructura social más compleja. No sólo el casco urbano se ensanchó, sino que en los principales escenarios urbanos del país ampliaron las bases de un proceso de modernización capitalista que se dinamizaría en los próximos años. Estos mismos cambios empezaban a verse también en el campo, con la presencia de las explotaciones agrarias de corte moderno, operadas por agricultores extranjeros que ingresaban al país y adoptaban el modelo farmer e introducían innovaciones tecnológicas importantes, entre ellas el uso del tractor. También, la contienda alentó un encuentro interclases: los campesinos pobres se encontraron con campesinos no tan pobres de otras zonas del país, los que a su vez conocieron a otros obreros, empleados, estudiantes y profesionales de clase media. La guerra también mostró otros mundos posibles y aumentó el desplazamiento poblacional hacia Asunción, y no sólo ello, el censo agropecuario de 1940 ya daba cuenta de un proceso de asalarización de los sectores campesinos jóvenes.

El 17 de febrero de 1936, un movimiento militar derrocó al liberal Eusebio Ayala (1932-1936) y lo reemplazó por el coronel Rafael Franco, el primer militar en custodiar la frontera boliviana y defender las primeras intervenciones militares, que aguardaba desde el exilio argentino por su intento de amotinar al Ejército (1931) contra el mismo presidente que ahora venía a reemplazar. Los dirigentes comunistas tuvieron una activa intervención en el movimiento: Obdulio Barthe, Facundo Duarte y Perfecto Ibarra participaron en la toma de la sede de la policía y el cuartel de la marina (Barthe, 2009, p. 77). La "revolución" aglutinó actores muy diferentes bajo el nacionalismo o, en estricto, el antiliberalismo. Con un ecléctico gabinete político, Rafael Franco juró como presidente en una plaza pública, leyó la Proclama del Ejercito Libertador, expresó su identificación con la obra de Francia y los López, declaró la caducidad de la Constitución liberal de 1870 y proclamó que el plebiscito era la nueva carta magna del Paraguay.

La Asociación Nacional de Ex Combatientes aportó la mayoría de la base política y funcionó como el partido del Gobierno junto con la Federación de Estudiantes y la recientemente formada Unión Femenina del Paraguay. El Gobierno de Rafael Franco fue además apoyado por la Confederación Nacional de Trabajadores (en adelante, CNT) y, luego, por la Confederación de Trabajadores Paraguayos como central obrera unitaria, dirigida por Francisco Gaona. La CNT incluía algunos sindicatos de mujeres cartoneras, cigarreras, costureras, lavanderas, y recogía la experiencia del Comité Sindical Clasista alentado por el PCP, que desde la clandestinidad venía trabajando en esa dirección.

E1 23 de febrero, el dirigente comunista Oscar Creydt-que había regresado al Paraguay después de siete años de exilio- reclamaba a través de la Radio Prieto que debía hacerse abstracción de las sustanciales diferencias de orientación que distinguían a los diferentes grupos que apoyaban la revolución, para formar un Frente Nacional Libertador. Creydt, consciente del anticomunismo presente en algunos núcleos afines a Franco, afirmaba que no era momento de hablar de la libertad de Eusebio 
Ayala y de medidas contra los comunistas que se disponían a sostener el gobierno. Advertía que cualquier paso en el sentido de desnaturalizar el significado del gobierno revolucionario conduciría a distanciarlo del pueblo, y expresaba su confianza en que el coronel Franco no se dejaría desviar (Seiferheld, 2012). Consideraba que el movimiento popular debía apoyar el proceso encabezado por Franco, a pesar de que éste no representaba los intereses de las clases obrera y campesina, ya que era una contención ante un posible golpe de Estado impulsado por sectores reaccionarios y grupos fascistas (Lo Bianco, 2014, p. 78).

Según los datos relevados por Víctor Jeifets y Lazar Jeifets (2015, p. 161), Obdulio Barthe llamó a la formación de un Frente Nacional Liberador, de manera similar a las experiencias de España y Francia, y ofreció el apoyo comunista al Gobierno recientemente constituido. Meses más tarde, en marzo del mismo año, a iniciativa de la CNT, nació el Partido Nacional Revolucionario, del cual el PCP decidió no participar. ${ }^{19}$

Según Antonio Maidana, reconocido intelectual y dirigente del PCP, "el Partido Comunista llamó a las masas a apoyar la insurrección armada comenzada por los veteranos de la guerra, con el fin de imprimirle al movimiento un carácter revolucionario, democrático, antifeudal y antiimperialista" (Bonzi, 2009, p. 98). La Comisión Militar del PCP se encargaba de trabajar con los excombatientes de la Guerra

19.E1 Frente Nacional revolucionario fue integrado por "La Confederación Nacional del Trabajo, la Asociación Nacional de Ex Combatientes de la Guerra del Chaco Boreal, la Federación de Estudiantes del Paraguay, la Agrupación Disidente del Partido liberal, la Liga Independiente, la Asociación Nacional Republicana (Partido colorado) y grupos de personas independientes" (Gaona, 2007, p. 26). del Chaco y el sector más radical, representado por la corriente estudiantil e intelectual, lograría imponer como ministro de Educación y Justicia a Anselmo Jover Peralta y estrecharía lazos con los ahora dirigentes del refundado PCP, Obdulio Barthe y Oscar Creydt. Un rol de igual importancia desempeñó el dirigente sindical Francisco Gaona, quien se incorporó al comunismo proveniente del sector socialista conducido por Rufino Recalde Milesi.

En una carta dirigida al Comité Ejecutivo de la Komintern, el comunista argentino Orestes Ghioldi evaluaba la situación paraguaya y la actuación de los comunistas había sido justa y permitido el aumento de afiliados, de 60 pasaron a 400 y ellos aseguran que más (Jeifets y Schelchkov, 2018, p. 1170).

El primer gran acto del movimiento de trabajadores -el 1 de mayo de 1936- se vivió, como un parteaguas de la historia política de los obreros y las obreras. Entre las organizaciones destacadas, estuvieron la Unión Femenina del Paraguay (en adelante UFP) (1936), ${ }^{20}$ organización dirigida por Dora Freis, casada con Obdulio Barthe. La única mujer en dar un discurso fue la comunista Rosa Schipper, quien ocupaba el lugar de tesorera en la primera comisión directiva de la UFP.

Sin embargo, las contradicciones del movimiento nacionalista se cristalizaron. Claramente, el presidente Rafael Franco estaba lejos de comandar un proceso revolucionario antiimperialista como los actores políticos de la época interpretaban. En su discurso apeló

20.La UFP fue un frente político de mujeres de diversas procedencias políticas que llegó a estar liderado por comunistas y que tuvo como programa político la ampliación de los derechos civiles y laborales. Una historia de la organización puede leerse en Soler (2017). 
a la prudencia y la serenidad, en tanto la obra revolucionaria se debía consumar de manera metódica y paciente, sin que "abrace la doctrina comunista” (Gaona, 2007, p. 69).

Pocos días después del 1 de mayo, la persecución policial se extendió a los dirigentes del Frente, de la CNT y de los sindicatos. Meses después, en octubre, el Decreto 5484 declaraba punibles las actividades comunistas y establecía las penas correspondientes, prohibiendo las actividades sindicales y político-partidarias, con la excepción de aquellas organizadas por la Revolución Febrerista.

En su carta a Moscú -firmada con el seudónimo de Morales-, Ghioldi (2018) manifestaba que la situación paraguaya había tenido una gran repercusión en Argentina y que los adversarios trotskistas habían aprovechado el giro anticomunista del Gobierno de Franco para atacar toda la línea del PCA "y por lo tanto han logrado meter algunas de sus ideas en nuestro Partido".

Las contradicciones del movimiento revolucionario llevarían rápidamente a su defunción. El 13 de agosto de 1937, Rafael Franco fue removido de la misma manera que había sido puesto: con un nuevo pronunciamiento de la Caballería. Diez años después, en plena guerra civil de 1947, el PCP fue prohibido, persecución que adoptó rango constitucional en los artículos de la Constitución stronista de 1967, en la que el Partido Comunista, "como cualquier otro género de organización totalitaria", no tendría derecho a ser inscripto ni reconocido.

\section{Conclusiones}

La constitución del PCP como sección paraguaya de la Internacional Comunista, - luego de una etapa signada por los primeros intentos de organización en la segunda mitad de la década de 1920-, tuvo lugar en coincidencia con la puesta en marcha del llamado "tercer período" y la orientación de "clase contra clase" impulsada por el VI Congreso de la Komintern (julio-agosto de 1928). Dos conferencias comunistas latinoamericanas organizadas en 1929 por la Komintern tendrán un crucial impacto: la Conferencia sindical en Montevideo y la Primera Conferencia de partidos latinoamericanos en Buenos Aires. Ante la agudización del conflicto territorial entre Bolivia y Paraguay, y la inminencia de la guerra, la organización comunista mundial impulsó movimientos antibélicos que en Paraguay fueron los Comités antiguerreros que lucharon por transformar la guerra en revolución social. El pequeño $\mathrm{PCP}$ estaba, según Jules Humbert-Droz, en una situación de gran responsabilidad, ya que era la primera de las secciones con la obligación de aplicar las tácticas comunistas contra la guerra. El tercer período implicaba como una cuestión fundamental el proceso de homogeneización o normalización de los partidos adherentes al Komintern. Sin embargo, la adecuación a la disciplina internacional da lugar a la primera crisis dentro del comunismo paraguayo, con la destitución del primer secretario general del PCP, Lucas Ibarrola, y la reorganización partidaria con la intervención del SSA.

A pesar del denodado esfuerzo desarrollado por los Comités antiguerreros y otras organizaciones antibélicas similares en la región, las actividades comunistas tuvieron escasa incidencia y no lograron modificar el curso de los acontecimientos. Las caracterizaciones 
mecanicistas de la guerra como conflicto interimperialista y las consignas radicales poco acordes con la fuerza efectiva de los partidos, aseguraron la ineficacia de todas las iniciativas. No obstante, en ese contexto tienen lugar los primeros acercamientos entre el incipiente comunismo paraguayo y el mundo de las organizaciones obreras hasta entonces hegemonizadas por tendencias anarquistas y socialistas.

Las transformaciones posteriores experimentadas por el comunismo paraguayo deben leerse en el marco general de un cambio de época propiciado por una coyuntura histórica significativa: un contexto nacionalista posbélico y el cambio de estrategia experimentado por la Internacional Comunista a partir de 1935. La confluencia de esos momentos concatenados explica buena parte de la fortaleza que logró el PCP en un contexto nacional muy hostil. La Guerra del Chaco abrió un proceso efectivo de politización y movilización nacional que afectó a amplios sectores: partidos políticos, ejército, iglesia, organizaciones obreras, campesinos y estudiantes.

Los años de la posguerra son un escenario propicio para observar cómo confluyen cambios internacionales y locales que impactaron directamente en los sujetos nacionales. E1 PCP reformuló sus estrategias no sólo por los nuevos lineamientos impuestos desde Moscú y por el abandono de una lectura exclusivamente en clave imperialista de las disputas entre naciones, sino también por la urgencia que impuso la coyuntura paraguaya a la vuelta de la guerra. De allí que el PCP pasara de ser la única organización del Paraguay en oponerse a la guerra del Chaco -conflicto bélico que gozaba de una extensa legitimidad local- a apoyar un Gobierno encabezado por un militar nacionalista que portaba como principal legado haber sido el primero en custodiar la zona fronteriza con Bolivia. No obstante, es en este período de posguerra y posibilitado en gran medida por la nueva estrategia aplicada, que se amplía la inserción del comunismo en el movimiento obrero.

$$
\propto \tilde{e} \propto
$$




\section{Referencias Bibliográficas}

Ansaldi, W. (Ed.). (2003). Tierra en llamas. América Latina en los años 1930. La Plata: Ediciones al Margen.

Barthe, O. (2009). Memorias inéditas. Capiatá: Talleres El Álamo.

Bonzi, A. (2009). Proceso bistórico del partido comunista paraguayo. Un itinerario de sombras y luces. Asunción: Arandurã.

Buzó Gómez, S. (2008). Cronología del movimiento obrero paraguayo. En F. Gaona, Introducción a la bistoria gremial y social del Paraguay. Tomo II. Asunción: Arandurã.

Caballero, M. (1985). La Internacional Comunista y la revolución latinoamericana, 1919-1943. Santiago de Chile: Centro de Estudios Chilenos/Ediciones Nuestra América.

Camarero, H. (2011). El tercer período de la Comintern en versión criolla. Avatares de una orientación combativa y sectaria del Partido Comunista hacia el movimiento obrero argentino. A Contracorriente. Revista de historia social y literatura de América Latina, 8(3), 203-232.

Churilov, E.M. y Petrujin, A.A (1994). Quebracho. Memorias de Antonio Maidana.Primera parte. Asunción: Biblioteca Hora Clave.

Fernández, C.J. (1987). La Guerra del Chaco. Vol. VII: Organizaciones civiles y militares de la retaguardia antes y durante la Guerra del Chaco. Asunción: Editorial Histórica.

Gaona, F. (2007). Introducción a la bistoria gremial y social del Paraguay, Tomo I y II, Asunción: Arandura.

Hernández, J. L. (2004). La internacional socialista y la Guerra del Chaco. En J. L. Hernández y G. Guevara (Comps.), La guerra como filigrana de la América Latina contemporánea (pp. 133-156). Buenos Aires: Editorial Dunken.

Hernández, J. L. (2016). El movimiento comunista y la guerra del Chaco (1932-1935). En L. Jeifets, V. Jeifets y M. A. Urrego (Coords.), Izquierdas, movimientos sociales y cultura politica en América Latina (pp. 105-128). Morelia: Instituto de Investigaciones Históricas, Universidad Michoacana de San Nicolás de Hidalgo/San Petersburgo: Centro de Estudios Iberoamericanos, Universidad Estatal de San Petersburg.

Jaritonov, V.A. (1980). Paraguay: Dictadura militar-policial y lucha de clases. La Habana: Editorial de Ciencias Sociales.

Jeifets, L. y Jeifets, V. (2012). The "International of Moscow" or the "International of Buenos Aires" The Comintern and the Paraguayan Communist Party. The International Newsletter of Communist Studies, 18(25), 123-136. Recuperado de https://incs.ub.rub.de/index.php/INCS/article/view/259

Jeifets, L. y Jeifets, V. (2013). El Partido Comunista de Argentina y la III Internacional. La misión de Williams y los orígenes del penelonismo. México DF: Nostromo Ediciones.

Jeifets, L. y Jeifets, V. (2015). América Latina en la Internacional Comunista, 1919-1943. Diccionario Biográfico. Santiago de Chile: Ariadna Ediciones. 
Jeifets, V. y Schelchkov, A. (Comps.). (2018). La Internacional Comunista en América Latina en Documentos del Archivo de Moscú. Santiago de Chile - Moscú: Ariadna Ediciones - Aquilo Press.

Lo Bianco, M. (2014). Oscar Creydt, Luces y Sombras. En Guillermo Ortega (Coord.), Pensamiento crítico en el Paraguay (pp. 75-93). Asunción: BASE-IS.

Miranda A. (1979). Apuntes para el desarrollo paraguayo, Vol.I. Asunción: Cromos.

Piemonte, V. A. (2015). Lucha de facciones al interior del Partido Comunista de la Argentina hacia fines de los años veinte: La “cuestión Penelón” y el rol de la Tercera Internacional. Cuadernos de Historia, (43), 31-58. Recuperado de https://cuadernosdehistoria.uchile.cl/index.php/CDH/article/view/41469

Piemonte, V. A. (2017). La Internacional Comunista y los comienzos del Secretariado Sudamericano a través de la sistematización regional del proceso de bolchevización. Historia Crítica, (64), 101-118. Recuperado de https://revistas.uniandes.edu.co/doi/pdf/10.7440/histcrit64.2017.06

Piemonte, V.A. (2016). Las prácticas políticas del Partido Comunista de la Argentina ante la Guerra Civil española y su relación con la Internacional Comunista. Historia Contemporánea, (52), 179-209. Recuperado de https:/www.ehu.eus/ojs/index.php/HC/article/view/15738

Quevedo, C. (2014). Mauricio Schvartzman y la tradición marxista en Paraguay. En G. Ortega (Coord.), Pensamiento crítico en el Paraguay (pp. 93-114). Asunción: BASE-IS.

Rivarola, M. (2013). El Paraguay liberal. En M. Rivarola y A. Boccia Paz (Comps.), Historia General del Paraguay. Tomo III. (pp. 15-175). Asunción: Fausto Ediciones.

Rivarola, M. (2014). Los orígenes del primer Partido Comunista paraguayo. Viento Fuerte, Asunción. Recuperado de http:/www.vientofuerte.com/news/2014/05/28/los-origenes-del-primer-partidocomunista-paraguayo/

Rivarola, M. (2015). La primera Reforma Universitaria paraguaya (1926-1929). Viento Fuerte, Asunción. http://www.vientofuerte.com/news/2015/10/13/la-primera-reforma-universitariaparaguaya-1926-1929/

Rosales, H. (2009). Historia del Partido Comunista Paraguayo (1928-1990), Juventud Comunista Paraguaya. Recuperado de http://www.lajota.org

Seiferheld, A. (2016). Nazismo y Fascismo en el Paraguay. Los años de la guerra 1936-1945. Asunción: Servilibro.

Soler, L. (2017). El Partido Comunista y la Unión Femenina del Paraguay en la coyuntura de los años 1930. En A. Valobra, y M. Yusta Rodrigo (Eds.), Queridas Camaradas. Historias iberoamericanas de mujeres comunistas, 1935-1975 (pp.113-132). Buenos Aires: Editorial Miño y Dávila.

Stefanoni, P. (2014). “Guerra a la guerra”: comunismo, antiimperialismo y reformismo universitario durante la contienda del Chaco. Revista Boliviana de Investigación, 11(1), (14-49). 